\title{
IMPLANTAÇÃO DE SISTEMAS ERP EM PEQUENAS E MÉDIAS EMPRESAS
}

ROCHA JUNIOR, Oswaldo Ricardo da ${ }^{1}$ MORAIS, Rinaldo Macedo de ${ }^{2}$

Recebido em: 2009-06-03

Aprovado em: 2009-09-29

ISSUE DOI: $10.3738 / 1982.2278 .233$

RESUMO: A utilização de softwares ERP (Enterprise Resource Planning) - ou de Gestão Empresarial - por pequenas e médias empresas, pode ser associada à uma decisão estratégica para alavancar os negócios ou como um "tiro no escuro", seguindo o modismo atual do meio empresarial. Este artigo discorre sobre o que é um ERP a fim de que pequenas e médias empresas possam observar as exigências técnicas para colocá-lo em operação e avaliar os impactos nesse processo.

Palavras-chave: ERP. Gestão Empresarial. Implantação de Sistemas

SUMMARY: The use of Entreprise Resource Planning software (ERP) by small or middle companies can be associated with a strategic decision to enhance the business or with a "bullet in the dark" - following the latest business trend. This work intents to present ERP systems, in order to provide means for small and medium sized companies can observe the technical requirements to consider the implementation and evaluate the impacts in this process.

Keywords: ERP. Enterprise Management. . Deployment Systems.

\section{INTRODUÇÃO}

Os pacotes de software ERP se difundiram entre as grandes corporações, acompanhando a evolução dos recursos disponibilizados por modernas tecnologias, como hardware para servidores dedicados, sistemas gerenciadores de bancos de dados e redes de alta velocidade, entre outros. Nessas corporações, existe toda uma estrutura organizacional que oferece suporte às questões operacionais do dia-a-dia no uso de tais softwares.

Nos últimos anos, as pequenas e médias empresas passaram a ter acesso às mesmas tecnologias usadas pelas grandes empresas, devido ao barateamento do custo de aquisição de hardware e software, tornando viável a utilização de sistemas ERPs em organizações desse porte. Porém, boa parte dessas empresas, em seu plano estratégico, direciona investimentos para atividades-fim, terceirizando atividades de suporte administrativo, como, por exemplo, contabilidade, recursos humanos e departamento fiscal,

\footnotetext{
${ }^{1}$ Bacharel em Sistemas de Informação pelas Faculdades Dr. Francisco Maeda da Fundação Educacional de Ituverava.

${ }^{2}$ Professor da Faculdade Dr. Francisco Maeda da Fundação Educacional de Ituverava.
} 
podendo causar deficiências no apoio técnico aos processos suportados por tais sistemas. Observa-se que um ERP exige de seus usuários um conhecimento mais detalhado das operações envolvidas em seu uso e em uma pequena ou média empresa o usuário nem sempre tem o conhecimento técnico suficiente para compreender e implementar as exigências de ajustes e parametrização, dependendo de consultoria externa para resolver esses problemas.

\section{TECNOLOGIA DA INFORMAÇÃO E SISTEMAS ERP}

A tecnologia da informação ocupa um papel-chave nas empresas, pois seu desenvolvimento proporciona suprir informações em mais curto espaço de tempo, visto que a globalização e automação dos processos produtivos também fazem parte do cenário mundial dos negócios (ALVARENGA, 2003), incluídos em um processo de concorrência direta. Uma das características da tecnologia de informação é ser totalmente desprovida da capacidade de produzir algo por si só. É notória a existência de exemplos de instituições que realizaram altos investimentos em tecnologia, mas não obtiveram os resultados desejados (BUENO; PIMENTA III; LICASTRO, 2000). A tecnologia usada sem inteligência não só produz resultados enganosos, como também trás perda de tempo e de recursos (JESUS; OLIVEIRA, 2007), porém a capacidade de aproveitar os recursos oferecidos pelas modernas tecnologias é crucial para a sobrevivência e sustentação no mercado, pois as organizações passam a possuir vantagens competitivas sobre seus concorrentes (ALVARENGA, 2003).

Em um cenário de demanda por agilidade, eficiência, flexibilidade e administração dos processos empresariais, os sistemas ERPs surgiram nos ambientes empresariais para

suprir as necessidades quanto à gestão dos negócios, valendo-se das atividades executadas por uma arquitetura multi-modular desenvolvida para oferecer funcionalidades às diversas áreas dentro de uma empresa, permitindo uma integração de todos os processos, conforme afirmam Jesus; Oliveira (2007) e Bueno, Pimenta III e Licastro (2000). Um ERP normalmente utiliza ou está integrado a uma base de dados relacional, pois deve garantir segurança, integridade, unicidade, disponibilidade, velocidade e centralização dos dados (GUSKUMA, 1999). Dentre os módulos que um ERP comumente disponibiliza, destacam-se, de acordo com Bueno; Pimenta III; Licastro, 2000):

- Contabilidade;

- Financeiro;

- Estoque e Almoxarifado;

- Faturamento;

- Recursos e Talentos Humanos;

Nucleus, v.6, n.2, out. 2009 
- Marketing;

- Produção Industrial.

Como definição, O ERP é uma arquitetura de software que tem por finalidade facilitar o fluxo de informações entre todos os setores de uma empresa, apresentando um ambiente amplo em soluções e informações, utilizando para tal um banco de dados único, operando em uma plataforma comum que interage com um conjunto de aplicações integradas, consolidando todas as operações do negócio em um simples ambiente computacional acessível a todos os usuários (Alvarenga (2003), Bueno; Pimenta III; Licastro (2000) e Guskuma (1999)).

Sob o ponto de vista histórico, o ERP é uma evolução do MRP (Material Requirements Planning) e do MRP II (Manufaturing Resource Planning), técnicas desenvolvidas desde a década de 1970 para automatizar os controles de suprimentos de materiais e da produção industrial. Percebendo as melhorias significativas que o MRP e MRP II causaram nos processos produtivos, surgiu a idéia de fazer o mesmo com relação a outras áreas da empresa (Alvarenga (2003), Bueno; Pimenta III; Licastro (2000), Guskuma (1999), e Jesus ; Oliveira (2007)).

Para implantar um sistema ERP, a necessidade de uma análise dos processos da empresa é imprescindível, além do treinamento dos colaboradores, investimentos em infraestrutura e reengenharia nos métodos de trabalho (BUENO; PIMENTA III; LICASTRO, 2000).

Um sistema ERP deve garantir que a entrada da informação seja efetuada uma única vez, e que esta informação fique disponível a qualquer tempo para qualquer módulo que dela necessitar (BUENO; PIMENTA III; LICASTRO, 2000). Um exemplo clássico é o cadastro de um novo cliente, cujas informações são passadas por um representante de vendas. Ao serem registrados no sistema pelo responsável do cadastramento, estes dados tornam-se disponíveis para o setor financeiro a fim de que sejam tomadas as devidas precauções quanto ao crédito do cliente, e assim poder liberá-lo para o faturamento. Após esta etapa, o faturamento pode lançar o pedido no sistema, usando o cadastro já existente do cliente. Caso algum item do pedido não tenha estoque suficiente para ser atendido, gera-se uma ordem de produção, que pode disparar vários outros processos, como uma solicitação de compras de matéria-prima. No fim de todos os processos, aquele pedido inicial torna-se uma nota fiscal de venda, faturada em nome do cliente informado lá no inicio, tudo isso sem a necessidade de redigitar qualquer informação do cliente já cadastrado. 


\section{CARACTERÍSTICAS DOS ERPs}

Conforme Souza (2000), Souza e Zwicker (2007), os sistemas ERP possuem seis características:

a) Os ERP são pacotes comerciais: A idéia básica da utilização de pacotes comerciais é atacar dois dos grandes problemas verificados na construção de sistemas através dos métodos tradicionais: o não-cumprimento de prazos e o estouro de orçamentos. Diversas alternativas têm sido usadas para atacar esse problema tais como a evolução das metodologias de desenvolvimento, prototipação, a utilização de ferramentas CASE e as linguagens e metodologias orientadas a objeto que têm como objetivo permitir a reutilização de componentes de software.

b) São desenvolvidos a partir de modelos-padrão de processos: Assim como os demais pacotes comerciais, os sistemas ERP não são desenvolvidos para um cliente específico e procuram atender requisitos genéricos da maior quantidade possível de empresas, justamente para explorar o ganho de escala em seu desenvolvimento. Para que possam ser elaborados, é necessária a utilização de modelos de processo de negócio, os quais são obtidos através da experiência acumulada pelas empresas, ou então elaborados por empresas de consultoria e pesquisa. Os sistemas ERP disponibilizam de um "catálogo" de processos empresarial que podem ser usados como referencial para o planejamento e mudança organizacional.

c) Integram os sistemas das diversas áreas da empresa: A integração pode ser definida como uma característica de sistemas de informação que consideram cada parte do sistema, servindo a um departamento específico da empresa, como parte de um único sistema empresarial, e não como uma série de sistemas isolados.

d) Utilizam um banco de dados corporativo: Entre as diversas maneiras de se desenvolver sistemas totalmente integrados está a utilização de um único banco de dados centralizado. Esse banco de dados é conhecido, também, como banco de dados corporativo.

e) Têm grande abrangência funcional: Uma diferença entre os sistemas ERP e os pacotes de software tradicionais é abrangência funcional daqueles, isto é, a ampla gama de funções empresariais cobertas por estes aplicativos.

f) Requerem procedimentos de ajuste: Todo sistema ERP é passível a algum tipo de adaptação para que possa atender aos requisitos do usuário. 


\section{TERMOS RELACIONADOS AOS SISTEMAS ERP}

Ainda Souza (2000), Souza; Zwicker (2007) apresentam alguns termos relacionados os sistemas de ERP, os quais são: a funcionalidade, a divisão em módulos, a parametrização, a customização, a localização e a atualização.

a) Funcionalidade: é o conjunto total de funções embutidas em um sistema ERP, suas características e suas diferentes possibilidades de uso.

b) Módulos: são os menores conjuntos de funções que podem ser adquiridos e implementados separadamente em um sistema ERP. Tais conjuntos de funções correspondem a divisões departamentais de empresas (vendas, financeiro, produção, planejamento da produção, entre outros).

c) Parametrização: é o processo de adequação da funcionalidade de um sistema ERP a uma determinada empresa através da definição dos valores de parâmetros já disponibilizados no próprio sistema.

d) Customização: é a modificação de um sistema ERP para que este possa se adequar a uma determinada situação empresarial impossível de ser reproduzida através dos parâmetros já existentes. Os custos de manutenção crescem, pois muitas vezes os fornecedores não dão suporte para rotinas altamente customizadas.

e) Localização é a adaptação (através de parametrizações ou customizações) de sistemas ERP desenvolvidos em outros países para a sua utilização na realidade brasileira (impostos, taxas, leis, procedimentos), Também é conhecido pelo termo "tropicalização".

f) Atualização: disponibilização dos aumentos nas funcionalidades e correções de problemas e erros.

\section{CICLO DE VIDA DE SISTEMAS E DE PACOTES COMERCIAIS DE SOFTWARE}

Conforme concordam Souza (2000), Souza; Zwicker (2007), Silva (2006), os ciclos de vida de sistemas são usados para representar as diversas etapas pelas quais passa um projeto de desenvolvimento e utilização de sistemas de informação. Em um ciclo de vida estão inseridas diversas etapas: levantamento de requisitos, definição de escopo do projeto, análise de alternativas, projeto do sistema, codificação, testes, conversão de dados e manutenção.

Dois modelos de ciclo de vida podem ser destacados: o modelo waterfall, em que as etapas são executadas em sequiência uma única vez para cada sistema, e os modelos que 
usam conceitos de prototipação, no qual sucessivas repetições de todas as etapas vão refinando incrementalmente o produto final até que esteja pronto para ser implementado.

O ciclo de vida de um sistema também passa a idéia de uma sucessão de fases de crescimento, evolução e declínio, e que ao final deve-se descartar o sistema, pois se tornou obsoleto, e substituí-lo por outro.

O ciclo de vida de pacotes comerciais não pode ser tratado como um desenvolvimento interno de aplicações, mas sim de uma aquisição de um pacote de sistema comercial desenvolvido externamente à empresa, e por ter características genéricas para atender diversas empresas, terá que sofrer adaptações durante a fase de implantação (SOUZA; 2000), (SOUZA; ZWICKER; 2007).

\section{CICLOS DE VIDA DE ERP}

Os sistemas ERP apresentam diferenças em seu ciclo de vida quando comparados aos sistemas tradicionais, e podem ser divididas em três etapas distintas, conforme Souza (2000) e também Souza; Zwicker (2007):

\section{- Etapa de Decisão e Seleção}

Ocorre uma única vez (um único sistema ERP deve ser escolhido para utilização de forma completa),

Deve-se considerar fatores envolvidos na utilização do ERP analisando vantagens e desvantagens.

A decisão pela utilização de ERP (a empresa deve levar em conta o alto investimento e o longo período de retorno, por isso o fluxo de caixa nesse período deve ser positivo), escolha do fornecedor (comparar alternativas, definir critérios e pesos nessa comparação são algumas ações propostas) e o planejamento da implementação (definição do líder de projeto, formação do comitê executivo, estruturação das equipes do projeto e a definição do plano geral de implementação) fazem parte desta etapa.

\section{- Etapa de Implementação}

É a segunda etapa do ciclo de vida do ERP (embora o termo seja usado para representar o ciclo completo).

Nesta etapa os módulos são colocados em funcionamento na empresa. 


\section{- Etapa de Utilização}

Nesta etapa começa-se a ter uma visão melhor do ERP como um todo, pois durante a implementação o esforço era concentrado em aderir o software à organização. Novos modos de usar a tecnologia disponibilizada começam a surgir.

\section{EXPECTATIVAS DAS EMPRESAS}

Quando se pensa em ERP, muitos empresários enxergam aí a solução de todos os seus problemas ligados à gestão de empresas, devido às expectativas de que o sistema impulsionará as atividades ligadas ao seu negócio da noite para o dia. As empresas esperam do ERP um pacote mágico que atinja todos os aspectos do negócio, e isto é uma visão distorcida da realidade (BUENO; PIMENTA III; LICASTRO, 2000).

Isto ocorre porque é dada uma maior atenção aos aspectos técnicos e financeiros (mensuráveis), deixando de lado os aspectos não técnicos, ligados à cultura e organização da empresa, conforme afirmam Alvarenga (2003), Bueno; Pimenta III; Licastro (2000), e Jesus; Oliveira (2007).

\section{CONSIDERAÇÕES FINAIS}

Para que as pequenas e médias empresas usufruam dos benefícios oferecidos por um ERP é preciso achar um meio-termo entre a simplificação dos processos de implantação, controle mais apurado nos custos do projeto, cronograma objetivo, e treinamento para os usuários-chave sobre os principais conceitos do sistema.

Os sistemas ERP exigem muito trabalho e dedicação dos profissionais envolvidos no processo de implantação, são mais complexos de operar e possuem custos mais elevados que pacotes comuns de software. Em contrapartida, são mais abrangentes, não possuem redundância de informações, integram os diversos setores da empresa, geram informações mais precisas e centralizam as informações em uma única base de dados.

Cabe agora às pequenas e médias empresas aceitarem o desafio e utilizarem uma ferramenta poderosa para a gestão de seus negócios, e também se tornarem mais competitivos no meio de um mercado tão exigente. 


\section{REFERÊNCIAS}

ALVARENGA, M.L. F. Metodologia para verificação do sucesso na implantação de ERP (Enterprise Resource Planning) baseada nos fatores críticos de sucesso - Aplicação na indústria mineira. 2003. Disponível em: <http://teses.eps.ufsc.br/defesa/pdf/10138.pdf〉. Acesso em 16 maio 2007.

BUENO, A. W. E.; PIMENTA III, D. de M.; LICASTRO, F. Sistemas ERP: requisitos, desafios e impactos da implantação nas empresas. 2000. Disponível em: <http://www.fea.usp.br/ead457/docs/Sem2S99/ERP\%20Implanta\%C3\%A7\%C3\%A3o.pdf>. Acesso em: 16 maio 2007.

GUSKUMA,E.A. ERP: A Solução final? 1999. Disponível em:

<http://www.fea.usp.br/ead457/docs/Sem2S99/ArtigoERP.pdf>. Acesso em: 16 maio 2007.

JESUS, R. G. de; OLIVEIRA, M. O. F. de. Implantação de sistemas ERP: tecnologia e pessoas na implantação do SAP $R / 3$. 2007. Disponível em:

<http://www.jistem.fea.usp.br/ojs/index.php/jistem/article/viewFile/65/65>. Acesso em: 10 set. 2007.

SILVA, E. M. O. da. Impacto de sistemas ERP no desempenho empresarial das indústrias de transformação da Região Metropolitana do Recife - RMR. 2006.

Disponível em: <http://www.unb.br/cca/pos-

graduacao/mestrado/dissertacoes/mest_dissert_088.pdf>. Acesso em: 11 set. 2007.

SOUZA, C. A. de. Sistemas integrados de gestão empresarial: estudos de casos de implementação de sistemas ERP. 2000. Disponível em:

<http://www.race.nuca.ie.ufrj.br/teses/usp/Souza.pdf>. Acesso em: 11 set. 2007.

SOUZA, C. A. de; ZWICKER, R. Um modelo de ciclo de vida de sistemas ERP: aspectos relacionados à sua seleção, implementação e utilização. 2007. Disponível em:

<http://www.ead.fea.usp.br/Semead/4semead/artigos/mqi/Souza_e_Zwicker.pdf >. Acesso em: 16 maio 2007. 